\title{
Using the Internet of Things Mobile to Keep the User's Back Straight While Sitting
}

\author{
Omar Elshaweesh (D), ${ }^{1}$ Mohammad Wedyan $\left(\mathbb{D},{ }^{2}\right.$ Ryan Alturki $\left(\mathbb{D},{ }^{3}\right.$ and Hashim Ali ${ }^{4}{ }^{4}$ \\ ${ }^{1}$ Department of Software Engineering, Information Technology College, AL-Hussein Bin Talal University, Ma'an 71111, Jordan \\ ${ }^{2}$ Department of Autonomous Systems, Faculty of Artificial Intelligence, Al-Balqa Applied University, Al-Salt 19117, Jordan \\ ${ }^{3}$ Department of Information Science, College of Computer and Information Systems, Umm Al-Qura University, \\ Makkah, Saudi Arabia \\ ${ }^{4}$ Abdul Wali Khan University Mardan, Mardan, Khyber Pakhtunkhwa 23200, Pakistan
}

Correspondence should be addressed to Omar Elshaweesh; omar.g.alshaweesh@ahu.edu.jo

Received 30 September 2021; Revised 30 October 2021; Accepted 24 November 2021; Published 16 December 2021

Academic Editor: Sikandar Ali

Copyright (C) 2021 Omar Elshaweesh et al. This is an open access article distributed under the Creative Commons Attribution License, which permits unrestricted use, distribution, and reproduction in any medium, provided the original work is properly cited.

Spine and neck pain is the most common type of pain experienced by people whose work requires sitting for long hours during the day. Therefore, many of them resort to dealing with this matter in several ways, and these methods differ in their effectiveness and negative effects. In this paper, we designed a device to alert the user to the need to adjust their sitting and to generate an alert when they are sitting inappropriately. When trying this device, the results were promising and accurate in terms of the results of the sequential reading of the movement of the flexible sensor, which helps the system to give alerts at the right time in the event of curvature of the spine, in addition to the ease of use of this device.

\section{Introduction}

The term Internet of Things (IoT) is a relatively recent term and refers to the new generation of the Internet that allows information exchange and understanding between different and interconnected devices. These devices may be sensors, tools, various artificial intelligence tools, and others [1]. It is also a modern technical method that aims to connect the things represented by sensors and various devices and connect them to the Internet to transfer data between these devices without human intervention if these things are within the geographical scope of the Internet $[2,3]$.

The phrase "Internet of Things" was coined in the late 1990s by businessman Kevin Ashton. He was one of the phrase members that connected things over the Internet; also, he first utilized this phrase in his presentation in 1999, and this term remained accompanying him ever since [4]. Only a few years ago, we started to see the true potential of the IoT, the concept of wireless Internet development became more prevalent, embedded sensors developed tremendously, and people started to understand the technology that could also be personal as a professional tool [5].

What distinguishes the IoT is that it allows the person to be free from the place, that is, the person can control the tools without having to be in a specific place to deal with a specific device [6]. It is noteworthy that the IoT lists below many of the daily things that can be integrated with it, and the principle of work is applied to them, such as industrial machines, wearable devices, and many others. It must be noted that the coming period of technological life will be buzzing with it as it is the best way to make life more efficient [7].

The domain of implementation of IoT technology is extremely big in daily life and has entered into several main areas and is among the most important of these areas that can be integrated with communications, health care, factories, companies, and education [7].

The applications of the IoT in the medical field are among the largest and most significant applications. IoT has decentralized healthcare services from healthcare 
institutions to lateralized sites such as homes and workplaces, making it one of the most widely used advancements in e-Health today. It can monitor patients remotely and record their conditions in electronic records, and it can also be applied in wearable systems to help control many healthy habits including patients' sleep patterns [8].

Furthermore, this domain is constantly confronted with significant interoperability issues. For example, the safe, secure, and successful sharing of clinical data between healthcare organizations or research institutes can offer significant operational challenges. Such clinical data exchanges necessitate extensive, trustworthy, and healthy engagement amongst the parties involved. The nature of clinical data, sensitivity, data-sharing agreements, processes, complex patient matching algorithms, ethical policies, and governing norms are all potential barriers in this process.

IoT technology works without the need for the intervention of the human factor; it works to communicate between more than one device or machine automatically and freely, or between a device and a person, and these devices have the freedom to exchange data and information and take action to act on it as well without asking for help or approval from the human factor.

The last industrial revolution has been considered as the technology of the IoT. Examples of commercial utilize the IoT: agriculture with pinpoint accuracy [9], intelligent parking [10], and management of water usage [11]. In addition, much research into the usage of IoT for constructing intelligent systems has been performed in different fields such as grids that are intelligent [12], crash-avoiding cars [13], and monitoring structural health [14].

Despite the fact that the aforementioned sectors appear to be drastically different from healthcare, the research undertaken within them supports the viability of an IoTbased healthcare system. Existing systems in other disciplines have demonstrated that remote object monitoring, data collecting, and reporting can be accomplished.

The entry of the IoT in the field of health is a golden opportunity and really important to meet the challenges of chronic diseases and also to prevent diseases before they occur. A patient's treatment by using IoT applications includes the use of built-in sensors and actuators. Invasive monitoring systems depend on the IoT aid in the continuous monitoring and tracking of a patient's physiological condition. Radio-frequency identification (RFID) technology was utilized to track the activity of medical practitioners and other healthcare providers washing their hands in one of Ohio's premier hospitals. The deployment of IoT-based technology helped enterprises minimize infection-related death tolls while also lowering financial losses $[15,16]$. The mechanisms of applying the IoT in the medical field differed from the development of healthcare systems and medical devices by reducing the duration of hospitalization, clinic visits, and death rates, which leads to obtaining the best clinical results [17]. The use of IoT in the development of medical devices meets the needs of a variety of healthcare fields. Figure 1 shows a variety of medical-related IoT-driven devices. The following section describes the methodology of this study in terms of study objectives and their importance.
In this study, we designed a smart device for people who use computers for long hours during the day, especially programmers, so as to keep their backbone straight. The device is installed on a person's backbone; if a person bends his backbone for more than two minutes, the person is alerted by vibration for half a second.

The rest of this paper is organized as follows. In Section 2 , system description is presented. Then, in Section 3, the components of the system are analyzed and presented. In Section 4, system implementation is presented. After that, Section 5 represents the results. Finally, the conclusion is presented in Section 6.

\section{Study Description}

Many people whose work requires sitting, especially programmers, suffer from a curvature of the backbone because of their wrong sitting, and then, these people begin to feel pain in the neck area and between the shoulders, fatigue, and exhaustion in the event of any activity or work, and if they continue to sit wrong for a long period, it will cause a twist in the backbone [30]. Therefore, many of these people resort to wearing back corset, which is used as a support tool to reduce the development of the situation for the worse. However, this corset has many negative effects because of which people use this corset less; the most important of it is as follows. (1) It works to stabilize the muscles (not moving). (2) Wearing the corset for long periods (for more than two or three hours) leads to a weakening of muscle strength [31]. Figure 2 shows the picture of a medical corset brace [32].

In this study, in the absence of a real tool that contributes and urges the practice of correct sitting, the device that we designed depends on alerting people and reminding them to adjust their sitting. In addition, with the passage of time in which this device is used, it contributes to training on a correct sitting. During the period of design of this device, we made sure to use low-cost materials so that anyone in society can own this device and to benefit all people who suffer from frequent curvature of the spine.

\section{The Components of the System}

This system contains six pieces electronics:

(i) Arduino UNO (Figure 3): it is considered as a microcontroller board consisting of a $16 \mathrm{MHz}$ ceramic resonator, reset button, 6 analog inputs, 14 digital I/O pins, USB connection facilitation, a power Jack, and ICSP header [33]. To operate the system, we use a USB cable or battery or power it with an AC-to-DC adapter to connect it to a computer [33, 34].

(ii) Flex sensor (Figure 4): it measures the amount of bending or deflection. It is installed on a specific surface, and bending the surface changes the resistance of the sensor element [35-37]. We need two from it.

(iii) Vibration sensor (buzzer) (Figure 5): it is an auditory signaling device that can be 
IoT Driven Devices

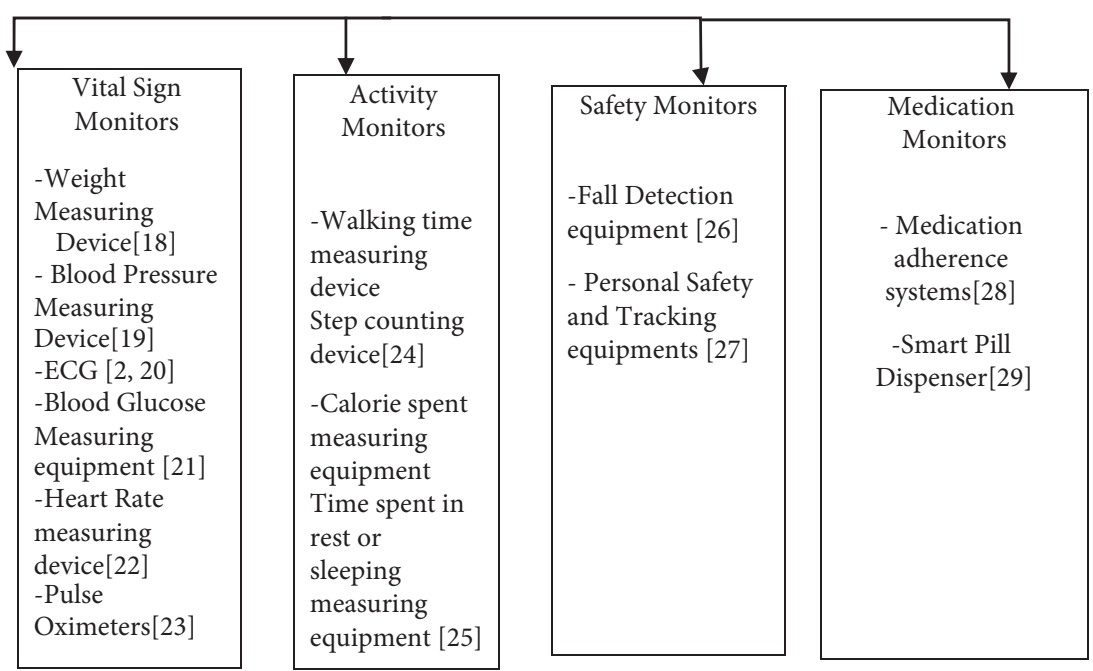

Figure 1: IoT medical devices [18-29].

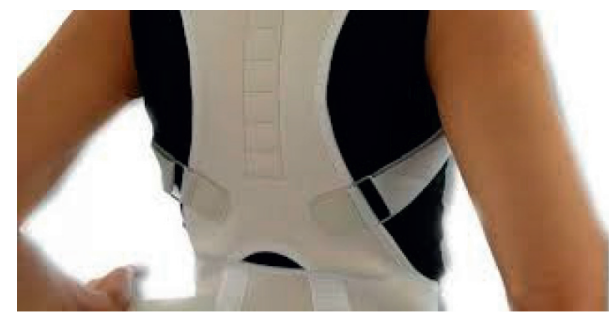

Figure 2: Medical corset brace [32].

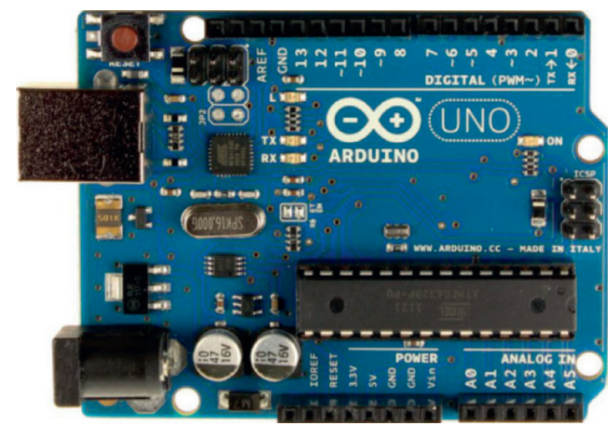

Figure 3: Arduino UNO [34].

electromechanical, mechanical, or piezoelectric in nature [38, 39]. We need two from it.

(iv) Female-female jumper wires (Figure 6): it is normally used to interconnect the components of an Arduino UNO with sensors [40].

(v) USB cable (Figure 7): it is used to connect the UNO with PC [41].

(vi) Breadboard (Figure 8): it is a building block for electronics prototyping [42].

Figure 9 shows the design of our project. We used the fritzing program and download it (https://fritzing.org/

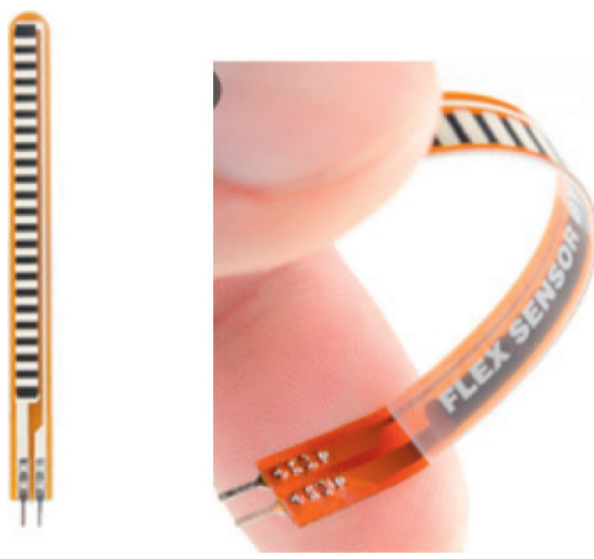

Figure 4: Flex sensor [35]

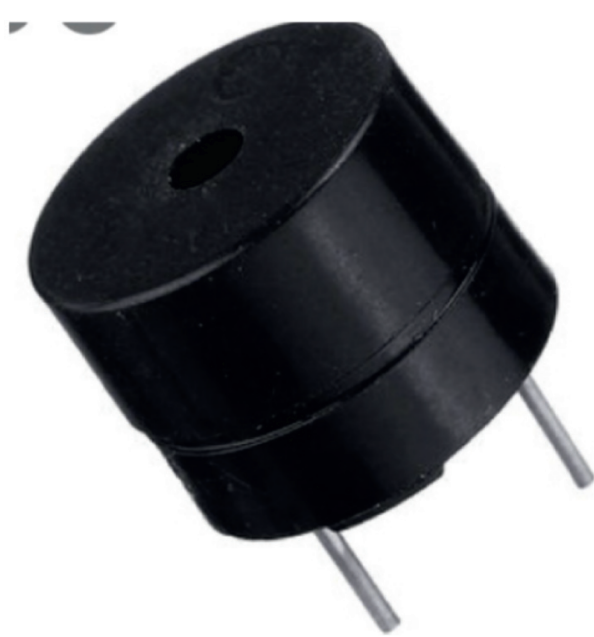

Figure 5: Vibration sensor (buzzer) [38].

download/) to experimentally design and draw this project. Figure 10 shows the algorithm used to implement this system. 


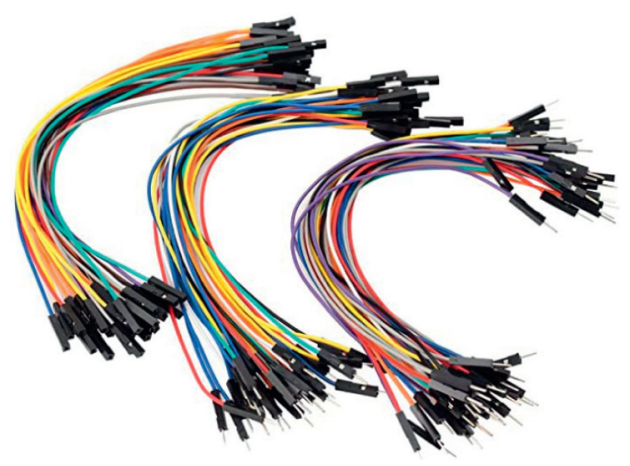

Figure 6: Female-male jumper wires [40].

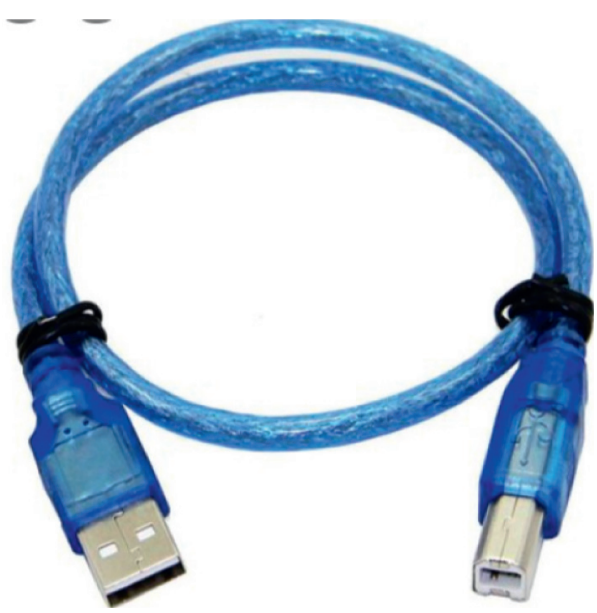

Figure 7: USB cable [41].

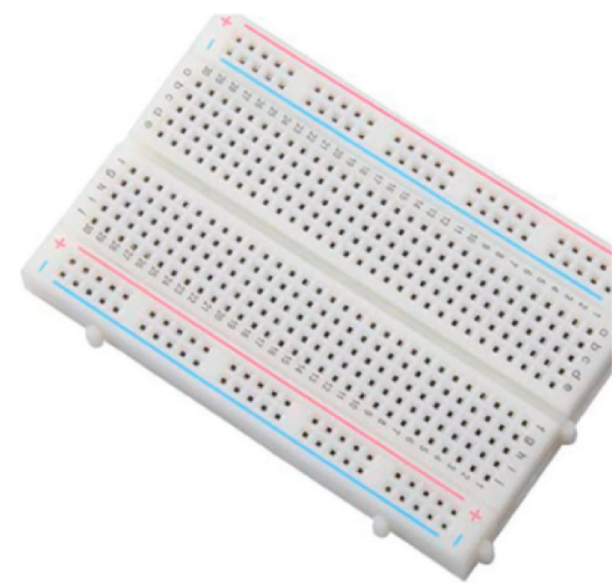

Figure 8: Breadboard [42].

\section{System Implementation}

The first flex sensor is installed longitudinally and the vibration sensor is next to it, on the upper part of the spine, as shown by the orange arrow in Figure 9. The second flex sensor is installed longitudinally on the bottom of the spine and the second vibration sensor next to it, as shown by the green arrow in Figure 9, so that both flex sensors take

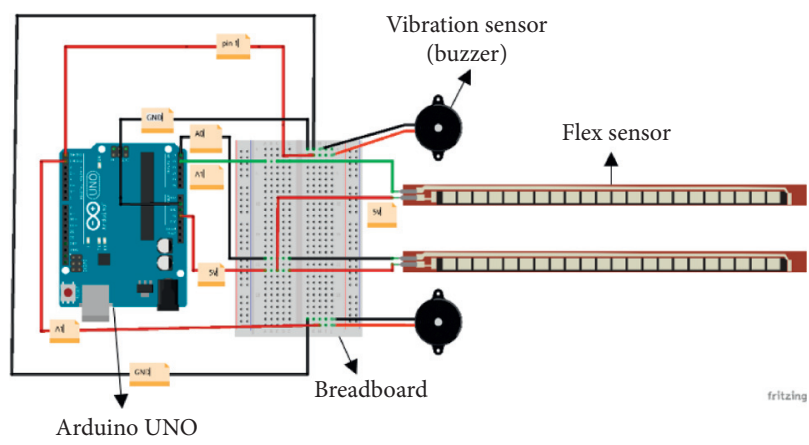

Figure 9: Project design.

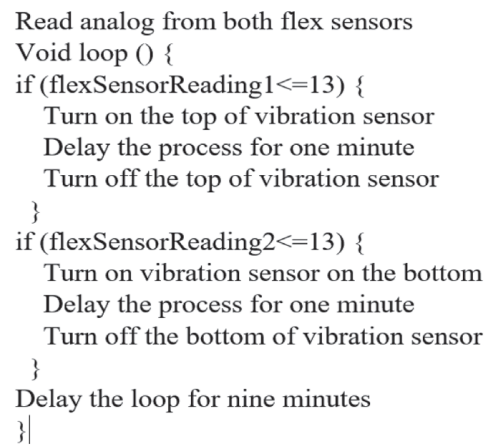

Figure 10: Algorithm of our system.

consecutive readings of the areas to which they are installed. If the user bends his backbone, see Figure 11, the vibration sensor starts, which is giving a shake for half a second to warn the person that he must adjust his seat.

\section{Results}

To carry out this experiment, we used Arduino software to get these results and downloaded it from https://www. arduino.cc/en/guide/windows. Arduino is programmed based on successive readings of the flex sensor. The vibration sensors work based on the reading of flex sensors.

The Arduino is programmed according to the following two levels:

(i) Level 1 (flex sensor reading<=13): alarm will work

(ii) Level 2 (flex sensor reading $==33$ ): alarm will not work

Figure 12 shows the output window of the serial monitor, which displays the alerts. In the beginning, the system displays the reading of flex sensors (in top and bottom). After that, if the reading of flex sensors is less than or equal to 13 that means the backbone is curved at 100 degrees, the vibration sensors are working for half second to remind the user of the device to adjust his sitting and shows "alarm working" message on the serial monitor, but if the reading of flex sensors is 33 , this means the backbone is straight and the vibration sensors are not working.

According to Figure 12, for example, 


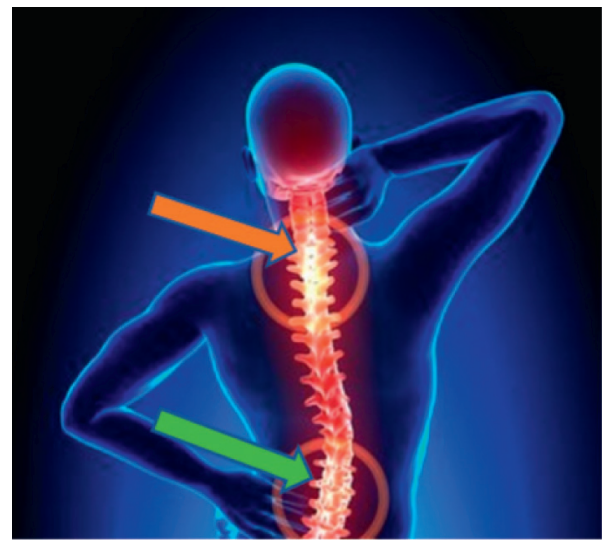

Figure 11: The places of install the flex sensors [43]. Note: this device is considered a prototype.

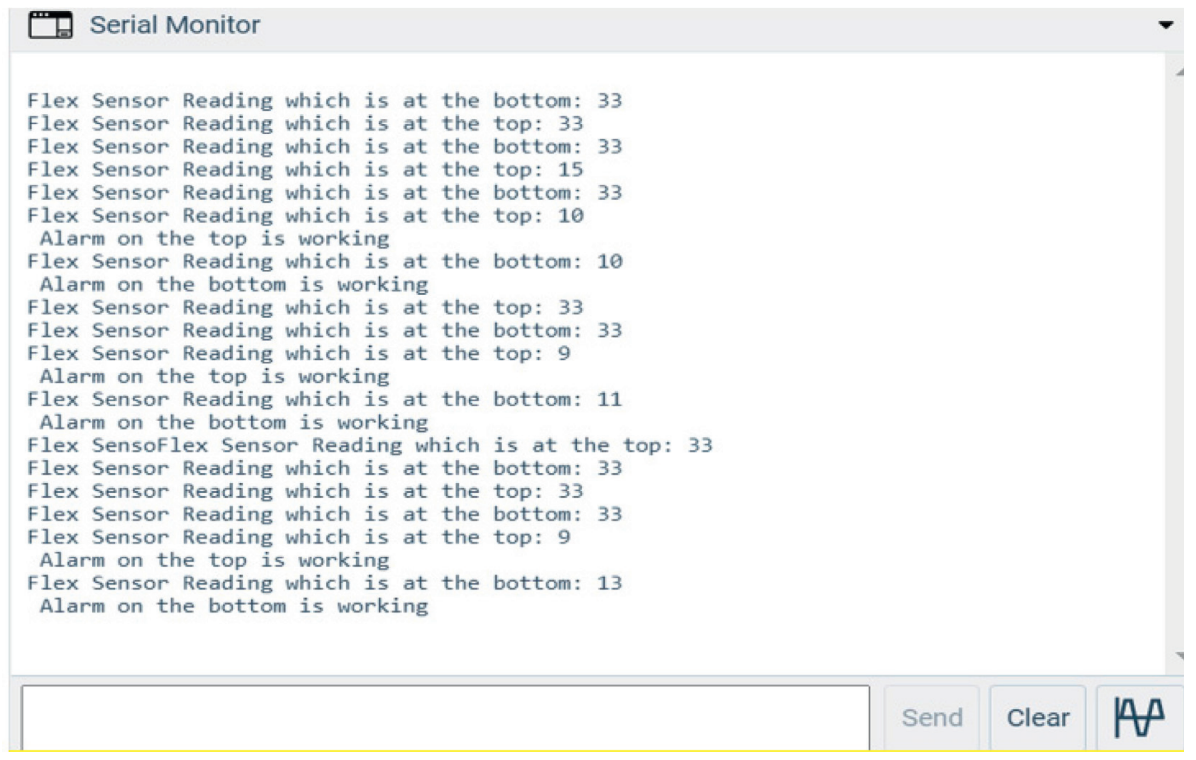

FIGURE 12: The output.

(i) The first five readings of the flex sensors (in top and bottom) > 13: alarm did not work

(ii) The sixth reading of the flex sensors $<=13$ : the alarm worked and gave a message on the serial screen stating that the sensor was turned on

\section{Conclusion}

Many people whose work requires sitting for long periods suffer from pain in the neck and spine. Therefore, many of these people resort to wearing back corsets, which are used as a support tool to reduce the development of the situation for the worse. However, this corset has many negative effects, including that it stabilizes the muscles (not moving), and wearing it limits muscle function. In this study, a smart alert system is designed to alert the person through an alarm so that this design helps to train the person to sit correctly. To bulid this devise, we needed to use two flex sensors, two vibration sensors, UNO, breadborad, and wires. Also, we have used Arduino software to program this devise. The most important features of this device are that it is easy to use and of low cost; the accurate reading of the bending sensors and giving the right alert to the user of this device helped us in the success of this device. This system is considered a prototype [32-43].

\section{Data Availability}

The data used to support the findings of this study are available from the corresponding author upon request.

\section{Conflicts of Interest}

The authors declare that there are no conflicts of interest regarding the publication of this paper.

\section{References}

[1] F. Xia, L. T. Yang, L. Wang, and A. Vinel, "Internet of things," International Journal of Communication Systems, vol. 25, no. 9, pp. 1101-1102, 2012. 
[2] A. Iftekhar and X. Cui, "Blockchain-based traceability system that ensures food safety measures to protect consumer safety and COVID-19 free supply chains," Foods, vol. 10, no. 6, p. 1289, 2021.

[3] K. Ashton, "That 'internet of things' thing," RFID Journal, vol. 22, no. 7, pp. 97-114, 2009.

[4] S. Gul, S. Ahmad, M. Yasir et al., "A survey on role of internet of things in education," International Journal of Computer Science and Network Security, vol. 17, no. 5, pp. 159-165, 2017.

[5] M. Kassab, J. DeFranco, and P. Laplante, "A systematic literature review on Internet of things in education: benefits and challenges," Journal of Computer Assisted Learning, vol. 36, no. 2, pp. 115-127, 2020.

[6] F. Wortmann and K. Flüchter, "Internet of things," Business \& Information Systems Engineering, vol. 57, no. 3, pp. 221-224, 2015.

[7] D. K. A.-R. Al-Malah, H. H. K. Jinah, and H. T. S. ALRikabi, "Enhancement of educational services by using the internet of things applications for talent and intelligent schools," Periodicals of Engineering and Natural Sciences, vol. 8, no. 4, pp. 2358-2366, 2020.

[8] M. Maksimović, V. Vujović, and B. Periśić, "A custom Internet of Things healthcare system," in Proceedings of the 2015 10th Iberian Conference on Information Systems and Technologies (CISTI), pp. 1-6, IEEE, Águeda, Portugal, June 2015.

[9] UON England, "Smart farm," 2017, http://www.une.edu.au/ research/research-centres-institutes/smart-farm.

[10] S. Parking, "Smarteye, smartrep, and RFID technology-Westminster city council-London," 2017, http:// www.smartparking.com/keep-up-to-date/case-studies/3-500vehicledetection-sensors-and-epermit-technology-in-thecity-of-westminsterlondon.

[11] Sensus, "Smart water-smarter at every point," 2017, http:// www.sensus.com/internet-of-things/smart-water.

[12] S. Tan, D. De, W.-Z. Song, J. Yang, and S. K. Das, "Survey of security advances in smart grid: a data driven approach," IEEE Communications Surveys \& Tutorials, vol. 19, no. 1, pp. 397-422, 2016.

[13] K. M. Alam, M. Saini, and A. E. Saddik, "Toward social internet of vehicles: concept, architecture, and applications," IEEE access, vol. 3, pp. 343-357, 2015.

[14] C. Arcadius Tokognon, B. Gao, G. Y. Tian, and Y. Yan, "Structural health monitoring framework based on Internet of Things: a survey," IEEE Internet of Things Journal, vol. 4, no. 3 , pp. 619-635, 2017.

[15] B. S. Babu, K. Srikanth, T. Ramanjaneyulu, and I. L. Narayana, "IoT for healthcare," International Journal of Science and Research, vol. 5, no. 2, pp. 322-326, 2016.

[16] J. Sun, F. Khan, J. Li, M. D. Alshehri, R. Alturki, and M. Wedyan, "Mutual authentication scheme for the deviceto-server communication in the internet of medical things," IEEE Internet of Things Journal, vol. 8, 2021.

[17] B. Singh, S. Bhattacharya, C. Chowdhary, and D. Jat, "A review on internet of things and its applications in healthcare," Journal of Chemical and Pharmaceutical Sciences, vol. 10, no. 1, pp. 447-452, 2017.

[18] P. Singh, "Internet of things based health monitoring system: opportunities and challenges," International Journal of Advanced Research in Computer Science, vol. 9, no. 1, pp. 224228, 2018.

[19] P. D. P. Adi and A. Kitagawa, "ZigBee radio frequency (RF) performance on raspberry pi 3 for internet of things (IoT) based blood pressure sensors monitoring," International Journal of Advanced Computer Science and Applications, vol. 10, no. 5, pp. 18-27, 2019.
[20] T. N. Gia, M. Jiang, A.-M. Rahmani, T. Westerlund, P. Liljeberg, and H. Tenhunen, "Fog computing in healthcare internet of things: a case study on ecg feature extraction," in Proceedings of the 2015 IEEE International Conference on Computer and Information Technology; Ubiquitous Computing and Communications; Dependable, Autonomic and Secure Computing; Pervasive Intelligence and Computing, pp. 356363, IEEE, Liverpool, UK, October 2015.

[21] J. J. Rodrigues Barata, R. Munoz, R. D. De Carvalho Silva, J. J. P. C. Rodrigues, and V. H. C. De Albuquerque, "Internet of Things based on electronic and mobile health systems for blood glucose continuous monitoring and management," IEEE Access, vol. 7, pp. 175116-175125, 2019.

[22] N. Xiao, W. Yu, and X. Han, "Wearable heart rate monitoring intelligent sports bracelet based on Internet of things," Measurement, vol. 164, Article ID 108102, 2020.

[23] Y. Xie, Y. Gao, Y. Li, Y. Lu, and W. Li, "Development of wearable pulse oximeter based on internet of things and signal processing techniques," in Proceedings of the 2017 European Modelling Symposium (EMS), pp. 249-254, IEEE, Manchester, UK, November 2017.

[24] T. Huiqiang, "Analysis of fluctuation factors of healthy exercise based on machine data mining and Internet of things," Environmental Technology \& Innovation, vol. 23, Article ID 101647, 2021.

[25] N. S. Ashfar, J. A. Lurther, and L. A. James, "FX calories calculator \& fitness advisor," International Journal on Cybernetics \& Informatics, vol. 10, 2021.

[26] A. Alarifi and A. Alwadain, "Killer heuristic optimized convolution neural network-based fall detection with wearable IoT sensor devices," Measurement, vol. 167, Article ID 108258, 2021.

[27] R. Rogers, "Internet of things-based smart healthcare systems, wireless connected devices, and body sensor networks in COVID-19 remote patient monitoring," American Journal of Medical Research, vol. 8, no. 1, pp. 71-80, 2021.

[28] X. Toh, H.-X. Tan, H. Liang, and H.-P. Tan, "Elderly medication adherence monitoring with the Internet of Things," in Proceedings of the 2016 IEEE International Conference on Pervasive Computing and Communication Workshops (PerCom Workshops), pp. 1-6, IEEE, Sydney, Australia, March 2016.

[29] M. V. Moise, A.-M. Niculescu, and A. Dumitraşcu, "Integration of Internet of Things technology into a pill dispenser," in Proceedings of the 2020 IEEE 26th International Symposium for Design and Technology in Electronic Packaging (SIITME), pp. 270-273, IEEE, Pitesti, Romania, October 2020.

[30] J. Hesse, "Medical back belt with neuromuscular electrical stimulation," in Smart Textiles and Their Applications, pp. 115-125, Elsevier, Amsterdam, Netherlands, 2016.

[31] O. Available, https://www.thecorsetcenter.com/7-pros-andcons-to-corsets/.

[32] 7-Doctores, [Online]. Available: https://7drs.com/\%D8\%A2\% D8\%AB\%D8\%A7\%D8\%B1-\%D8\%A7\%D8\%B3\%D8\%AA\% D8\%AE\%D8\%AF\%D8\%A7\%D9\%85-\%D9\%85\%D8\%B4\% D8\%AF\%D8\%A7\%D8\%AA-\%D8\%A7\%D9\%84\%D8\%B8\% D9\%87\%D8\%B1-\%D8\%A7\%D9\%84\%D8\%B9\%D8\%B4\% D9\%88\%D8\%A7\%D8\%A6\%D9\%8A\%D8\%A9/.

[33] A. UNO, [Online]. Available: https://www.jsumo.com/ arduino-uno-r3-clone-with-usb-cable-usb-chip-ch340.

[34] F. sensor, [Online]. Available: https://www.teachmemicro. com/use-flex-sensor/.

[35] buzzer, [Online]. Available: https://www.pcboard.ca/ minipiezo-buzzer. 
[36] F.-M. J. Wires, [Online]. Available: https://www.amazon. com/Female-Female-Jumper-Wires-pcs/dp/B079QPFMPT.

[37] U. C. f. UNO, [Online]. Available: https://www.circuituncle. com/product/usb-cable-for-arduino-uno-mega/.

[38] N. S. Kumar, B. Vuayalakshmi, R. J. Prarthana, and A. Shankar, "IOT based smart garbage alert system using Arduino UNO," in Proceedings of the 2016 IEEE Region 10 Conference (TENCON), pp. 1028-1034, IEEE, Singapore, November 2016.

[39] A. Syed, Z. T. H. Agasbal, T. Melligeri, and B. Gudur, "Flex sensor based robotic arm controller using micro controller," Journal of Software Engineering and Applications, vol. 5, 2012.

[40] M. Wedyan, A. Al-Jumaily, F. Alnajjar, P. M. Muhamed, and S. Shimoda, "A wearable robotics assistive device: design, technical solutions, and implementation," in Proceedings of the 2017 International Conference on Electrical and Computing Technologies and Applications (ICECTA), pp. 1-5, IEEE, Ras Al Khaimah, UAE, November 2017.

[41] J. Christian and N. Komar, "Prototipe sistem pendeteksi kebocoran gas LPG menggunakan sensor gas MQ2, board Arduino duemilanove, buzzer, dan Arduino GSM shield pada PT. Alfa retailindo (carrefour pasar minggu)," Jurnal TICom, vol. 2, no. 1, p. 92830, 2013.

[42] Breadboard, [Online]. Available: https://www.amazon.com/Qunqipoint-Experiment-Breadboard-5-5\%C3\%978-2\%C3\%970-85cm/ dp/B0135IQ0ZC/ref=asc_df_B0135IQ0ZC?tag=bingshoppinga20\&linkCode $=$ df0\&hvadid $=79989522876977 \&$ hvnetw $=$ o\&hvqmt $=$ e\&hvbmt $=$ be\&hvdev $=c \&$ hvlocint $=\&$ hvlocphy $=$ \&hvtargid $=$ pla- $4583589111108674 \& p s c=1$.

[43] I. O. backbone, [Online]. Available: https://www.albayan.ae/ balsam/news/2015-12-06-1.2522862. 